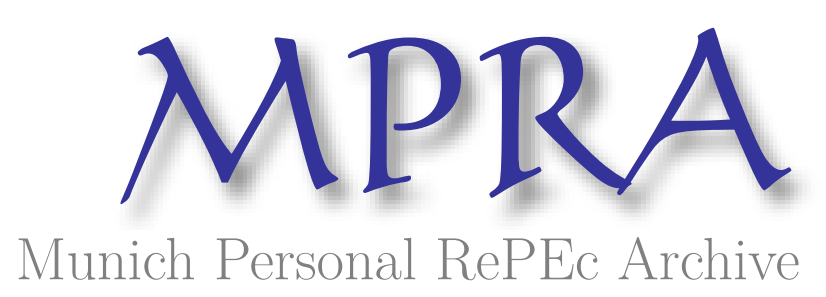

\title{
Exploration for human capital: Theory and evidence from the MBA labor market
}

Kuhnen, Camelia M. and Oyer, Paul

Northwestern University - Kellogg School of Management, Stanford Graduate School of Business

8 June 2012

Online at https://mpra.ub.uni-muenchen.de/39411/

MPRA Paper No. 39411, posted 12 Jun 2012 17:18 UTC 


\title{
EXPLORATION FOR HUMAN CAPITAL: THEORY AND EVIDENCE FROM THE MBA LABOR MARKET*
}

\author{
Camelia M. Kuhnen ${ }^{\dagger}$
}

\author{
Paul Oyer
}

June 2012

\begin{abstract}
Drawing on insights from corporate finance and personnel economics, we show that firms consider potential employees using a real options approach, much as they do when making other types of capital investment decisions. Theoretically we find that firms' hiring decisions are influenced by the uncertainty in workers' productivity, competition in the labor market, adjustment costs, and redeployability concerns. Firms value probationary employment arrangements that provide the option to learn about the productivity of potential hires before permanent investment occurs. Higher uncertainty and adjustment costs hinder permanent investment and increase the value of the option to learn. Greater competition for workers speeds up firm investment and increases the value of probationary employment. Higher worker redeployability leads to more investment, if firms face sufficiently low competition. We test and confirm these predictions empirically using a novel dataset with detailed recruiting information from the labor market for MBA graduates.

JEL Classification: G31, M51, J44.
\end{abstract}

*We thank Steven Grenadier, Robert McDonald, Derek Neal, Scott Schaefer, Kelly Shue, and participants at the 2011 NBER Personnel Economics Summer Institute, 2012 ASU Winter Finance Conference, 2012 NBER Organizational Economics, 2012 FIRS Conference, 2012 IZA-SOLE Transatlantic meeting, and seminar participants at U.C. Berkeley and Queen's University for their comments and suggestions. All remaining errors are ours. The Zell Center for Risk Research at Kellogg provided generous financial support for this work.

†Department of Finance, Kellogg School of Management, Northwestern University, 2001 Sheridan Road, Evanston, IL 60208-2001, c-kuhnen@kellogg.northwestern.edu.

†Stanford University Graduate School of Business and NBER, 655 Knight Way Stanford, CA 94305-7298, pauloyer@stanford.edu. 


\section{Introduction}

As the value of skill has risen in the developed economy over time, many firms rely on finding and developing the right people to remain competitively viable. But how do firms invest in human capital? In many ways, the decision to invest in people is similar to the decision to invest in physical assets. ${ }^{1}$ Uncertainty about the profit generated by the investment, as well as competition, adjustment costs, and redeployability concerns are likely to influence which workers firms hire. All of these factors are important for the firms' decision to make investments in physical capital, due to their real options' features (e.g., delay, expand, or abandon), as shown by a large literature in corporate finance and macroeconomics (Dixit and Pindyck (1994), Trigeorgis (1996)). The goal of this paper is to investigate the extent to which uncertainty, competition, adjustment costs, and redeployability considerations impact human capital investments. ${ }^{2}$

The novel contribution of our paper is to combine insights from the finance literature on real options and from the labor and personnel economics literature on employer-employee matching and job search to provide a theoretical and empirical analysis of the process by which firms select employees. ${ }^{3}$ We derive a model of how firms value probationary or contingent employment arrangements that provide the "option to learn" about the productivity of potential hires. We model how a firm's willingness to take a chance on a worker responds to features previously studied in the context of real options of physical capital - uncertainty about productivity, turnover costs (the labor market equivalent of adjustment costs), redeployability across employers, and the competitiveness of the labor market faced by the firm. We then test the model using novel data from the market for fresh MBA graduates. ${ }^{4}$

\footnotetext{
${ }^{1}$ The term "Human Capital", coined by Schultz (1961), captures this idea and suggests that firms' choice of employees, as well as employee skills and knowledge, are the result of deliberate investment.

${ }^{2}$ While some attention has been paid to the real option of hiring workers in managerial practitioner papers (e.g., Foote and Folta (2002)), only a few economic papers have studied this issue (Lazear (1998) and Hendricks, DeBrock and Koenker (2003)).

${ }^{3}$ See Oyer and Schaefer (2011) for details about the successes and limitations of the economics literature on employer/employee matching. For empirical evidence on firm/worker matching focused on senior executives, see Bandiera, Guiso, Prat and Sadun (2010) and Graham, Harvey and Puri (2010). They show that firms that offer stronger incentives employ managers who are more risk tolerant and more talented, and that managerial characteristics such as risk aversion match these firms' project types. Kaplan, Klebanov and Sorensen (forthcoming) document that personality characteristics influence firms' choice of executives and correlate with performance.

${ }^{4}$ Data on MBA graduates has recently been used in other economics and finance research. For example,
} 
We first show theoretically that firms value probationary employment arrangements that provide the option to learn about the productivity of potential hires before permanent investment occurs. Higher uncertainty and adjustment costs hinder permanent investment and increase the value of the option to learn. More competition for workers speeds up firm investment and increases the value of probationary employment, while greater worker redeployability leads to more investment if firms face sufficiently low competition.

We then test these predictions empirically using a novel dataset with detailed recruiting information from the labor market for MBA graduates, and find general support for the model. Not surprisingly, we find that all firms prefer to hire students with high general ability and experience in their industry. We also show that a large fraction of job applicants have unknown industry fit, which creates uncertainty regarding their future productivity. We document that employers highly value the option to learn about candidates lacking industry experience by making significant use of cheap probationary employment - namely, summer intern positions after the students' first year in the MBA program. The interest in exploring workers with unknown fit is significantly higher at the internship recruiting stage, relative to the full-time recruiting stage which occurs in the students' second year of MBA study. This is particularly true for firms characterized by high turnover costs, such as small companies. Higher competition increases the number of job offers that firms make at the internship stage relative to the full-time stage, increasing the importance of probationary employment as a channel for permanent investment in human capital. Finally, we document that firms are more likely to invest in more redeployable workers. Specifically, they prefer applicants with high general ability as measured by their GPA for both probationary and permanent jobs, particularly if there is less uncertainty about industry fit.

The model and our empirical results highlight important similarities between investment in human and physical capital, as well as critical differences. Both people and physical capital are inputs into the firms' production function, and are associated with generating revenues and incurring expenses. It is therefore natural to expect that for both types of assets, uncertainty about the cash flows they will produce, the costs of changing strategies upon the revelation of new information about productivity, and the competitiveness of the

Shue (2011) finds that networking through MBA education leads executives to exhibit commonalities in firm policies. Sapienza, Maestripieri and Zingales (2009) show that MBA students low in risk aversion are more likely to work in higher risk finance jobs after graduation, while Kaniel, Massey and Robinson (2010) find that optimistic MBA students receive job offers faster than their peers. 
market in which the firm operates will be critical determinants for the decision to invest. Theoretical work regarding physical capital investment decisions proves that it is valuable for firms to wait and learn more about future product market conditions before starting or abandoning a project (Brennan and Schwartz (1985), Titman (1985) and McDonald and Siegel (1986)). The option to wait for the resolution of uncertainty is more valuable for investments with a higher degree of irreversibility, which may come from higher capital adjustment costs or a lower degree of asset redeployability, and for firms operating in less competitive markets (Caballero (1991), Williams (1993), Grenadier (2002)). These predictions have been verified empirically in the context of real estate valuation and development (Quigg (1993), Cunningham (2007), Bulan, Mayer and Somerville (2009)), offshore petroleum lease acquisitions (Paddock, Siegel and Smith (1988)), mining operations (Moel and Tufano (2002)), and manufacturing (Guiso and Parigi (1999)).

However, human and physical capital differ in important ways that call into question the relevance of the results documented regarding physical investments when trying to understand the firms' decision to invest in human capital. First, the nature of uncertainty in the two contexts is different. Typically, the source of uncertainty about physical capital investments comes from future demand in the product market. For example, an oil exploration firm is concerned with whether future oil prices will be high or low, and may want to wait for less uncertain times before incurring the exploration costs. Therefore, variability in such settings has an intertemporal nature. In human capital investments, concerns about uncertainty regarding product market demand may be of lesser importance relative to concerns about the inherent heterogeneity of human capital. No potential employee has a perfect substitute and each employee's scale is limited, so firms cannot buy more of the same human capital input or know its productivity perfectly. This leads us to focus more on the "option to learn" as the firm determines the value of the asset (i.e, the employee) over time rather than on the "option to wait" for information revelation in the product market. ${ }^{5}$ Lazear (1998) also considers the option to learn in a labor market context, stating condi-

\footnotetext{
${ }^{5}$ Kahn and Lange (2011) point out another part of employee heterogeneity that is more analogous to the "option to wait" in real option models of physical capital by considering the fact that workers' productivity is constantly changing and that these changes differ across people. This suggests that firms might value both the "option to learn" and the "option to wait" on employees as they do with other assets (see Grenadier and Malenko (2010)), so that they can see how a given worker's productivity develops. However, because our empirical analysis focuses (due to data availability) on the initial firm/worker match, we cannot analyze this form of option value.
} 
tions under which hiring risky workers can be a profit-maximizing strategy for firms. Given the institutional context we study empirically, our approach differs from Lazear (1998) in a few key ways. We allow for more flexible industry-specific and firm-specific productivity, and, in our model, wages do not vary across firms. Our data and these refinements to the model allow us to address the comment by Oyer and Schaefer (2011) that there is scarce work examining across-firm variation in the propensity to hire risky workers, or whether the observed variation fits with Lazear's theory.

Second, the nature of competition may be different. The real options literature concerning physical capital has focused mostly on competition for output in the product market (e.g., Grenadier (2002)) and its implication for the timing of investment in the face of uncertainty. A notable exception is Abel, Dixit, Eberly and Pindyck (1996), who suggest that variation in the market value of the inputs deployed in production should also be a determinant of the timing and size of corporate investment. Arguably, in the case of human capital investment, considerations regarding the competition for inputs (i.e., the workers themselves) are critical.

Third, the nature of the asset's redeployability is different in the two contexts. For physical capital investments, higher asset redeployability lessens the irreversibility of the investment and the importance of resolving uncertainty for the timing of projects, as the loss incurred when the capital stock is sold or adjusted is lower (e.g., Guiso and Parigi (1999)). Hence, high asset redeployability speeds up permanent physical investment. In the context of human capital investments, however, high redeployability of a potential worker is equivalent to this individual having more generally applicable skills, which can be deployed elsewhere without any compensation (or recouping of investment costs) for the current employer. This suggests that firms in competitive environments characterized by some uncertainty in the profit function and capital adjustment costs may delay investing in workers characterized by high redeployability. This effect may be reversed, though, if waiting is associated with a lowering of the quality of workers available at a later time, which is a concern not typically considered in the case of physical investments.

Finally, capital adjustment costs are likely to influence physical and human capital investment decisions in similar ways, as in both settings they capture the idea that it is costly to scale up and scale down the capital stock (or hire and fire people) because of frictions in asset or labor markets. Therefore, high capital adjustment costs, which are typically referred to as turnover costs in the case of human capital, may slow down investment in the presence 
of uncertainty.

These similarities and differences in real options considerations regarding physical and human assets are captured by our model and empirical findings. In line with results from the physical investments literature, we show that uncertainty and adjustment costs hinder permanent investment and increase the value of the option to learn about worker productivity. Different from implications from the physical investments literature, we find that higher competition for human capital increases the value of probationary employment arrangements as a channel for hiring. Higher redeployability of human capital leads to more investment only if firms face low enough competition for workers, and especially if uncertainty about productivity is low.

Probationary or temporary employment arrangements similar to the summer interships we consider are widespread and continue to gain importance. This type of employment has been shown to be a stepping stone to permanent employment, accounting for a significant percentage of jobs across the world: for example, 10\% in the U.K. (Booth, Francesconi and Frank (2002)) and 35\% in Spain (Guell and Petrongolo (2007)). Using U.S. survey data, Houseman (2001) reports that temporary and part-time workers are employed by $46 \%$ and $72 \%$ of business establishments, respectively. While providing firms with flexibility to weather changes in the economic environment (Segal and Sullivan (1997), Levin (2002)) (i.e., providing the "option to wait"), temporary and contract employment is also valued for offering firms the option to learn about the quality of workers. In the U.S. survey sample constructed by Houseman (2001), 21\% of employers using temporary workers from agencies and 15\% using part-time workers cite screening as an important reason for using these types of work arrangements. Also illustrating the value of the firms' option to learn about worker productivity, Guell and Petrongolo (2007) find that Spanish workers with better outside options are better at converting temporary work arrangements into permanent positions.

Getting a better understanding of the matching process in high-skill environments such as the one studied here is important, given the increasing prevalence of graduate degrees and the significant role of high-skill and professional labor markets in the economy. The process of matching firms and employees early in their career is also particularly interesting to study, in light of the strong impact of these initial matches on long-term employment and productivity (Oyer (2008)). Given the anecdotal suggestions of a recent renewal of the "War for Talent", our model and empirical results provide some guidance on what employers are 
searching for in at least one high-talent market. ${ }^{6}$

Our paper builds on and contributes to work in other areas of labor economics and finance. For example, we build on the matching model of Jovanovic (1979), as we allow idiosyncratic fit to influence the efficient matching of firms to workers. The positive assortative matching between firms and workers that we obtain here is in the spirit of predictions in Gabaix and Landier (2008) and Tervio (2008), who model the matching of CEOs to firms and its implications for output and wages. In our setting, where wages are assumed to be standardized, this result is driven by the fact that more prestigious firms have better odds of having their offers accepted by high ability job candidates, and not because these firms offer higher wages to more productive workers. The specifics of the labor market learning process we consider during summer internships has many of the features of the learning model in Farber and Gibbons (1996). However, in our context, wages do not adjust to match expected productivity so we cannot make predictions about the relationship between wages and other variables. Like Farber and Gibbons (1996), all learning in our model is public information. Firms choose employees based partially on their match-specific productivity (or preferences). This gives incumbent firms some of the advantages enjoyed by firms with an informational advantage in models such as Waldman (1984) and Greenwald (1986). It also leads to an "unraveling" effect where the average quality of available employees is higher in the summer internship phase than in the permanent hiring phase.

Our paper also complements the emerging finance literature regarding the role of workers on corporate decisions and outcomes. For example, the firms' workforce characteristics have been shown to influence capital structure choices, theoretically and empirically (e.g., Berk, Stanton and Zechner (2010), Agrawal and Matsa (2011)), as well as the cost of capital (Eisfeldt and Papanikolaou (forthcoming)). The acquisition of productive labor, not just physical assets, is an important driver of M\&A decisions (Ouimet and Zarutskie (2011)).

We present a simple model of hiring in the MBA labor market in the next section of the paper. We describe the dataset in Section 3. Section 4 contains the empirical analysis, as well as a discussion of its limitations. Section 5 concludes.

\footnotetext{
${ }^{6}$ The business press and blogs are full of talk of a reviving war for talent as we write this. According to the PricewaterhouseCoopers' 2011 Annual Global CEO survey, "Talent tops the CEO agenda for 2011, across all regions." (http://www.pwc.com/gx/en/ceo-survey/talent-search.jhtml). Numerous recent articles have detailed hiring battles for new graduates between Facebook, Google, and other technology companies. See, for example, "Google Battles to Keep Talent," by Amir Efrati and Pui-Wing Tam, Wall Street Journal, November 11, 2010.
} 


\section{A Stylized Model of Hiring}

\section{$2.1 \quad$ Setup}

In this section, we develop a simple model of hiring. The model captures many of the general hiring and matching challenges firms face, but is adapted to the MBA context which we will study empirically.

We assume that productivity is a function of three factors - an individual's general ability (skills that are equally useful to multiple employers), industry-specific skills, and a match quality idiosyncratic to a given firm/worker pair. Our model focuses on a single firm's actions, at each of two stages of the hiring process: a try-out (i.e., internship recruiting) stage and a permanent employment (i.e., full-time recruiting) stage.

Each person has either high general ability $(H=1)$ or low general ability $(H=0)$. This is public information (known to potential employers of MBA students through grades, GMAT scores, etc.) For a given firm, the fraction of applicants with $H=1$ in the initial stage applicant pool is given by $\phi_{a, 1}$.

Each potential new hire is either a good match for the firm's industry $(M=1)$ or a bad match $(M=-\infty) \cdot{ }^{7} M$ is not known until the person works in the industry but it becomes publicly known with certainty once he works there. Let $\phi_{b}$ represent the fraction of a given firm's applicant pool, conditional on not having previous experience in the firm's industry, with $M=1$. We assume that all applicants who do have industry experience have $M=1$. That is, if a person is a bad match for an industry, she will never apply to work there (either because she understands it is not her best option or because she knows firms will not make her an offer.) This insures that, even if a person is an excellent fit for a specific firm, she will not want to work for that firm if she is a bad fit for the firm's industry.

Before hiring (from the interviewing and reference processes), the firm learns each potential worker's match-specific productivity, $\varepsilon$, which is distributed uniformly from $-\sigma$ to $\sigma$ with distribution $f(\varepsilon)=\frac{1}{2 \sigma}$ and $\operatorname{CDF} F(\varepsilon)=\frac{\varepsilon+\sigma}{2 \sigma}$. Modeling in detail the process by which the employer learns about match productivity is not particularly interesting in our

\footnotetext{
${ }^{7}$ We focus on the value of the match between a worker and an industry early in a career. However, this could also be interpreted as industry-specific human capital that builds very quickly. While most of the prior work on worker/industry matching has focused on specific human capital built up throughout longer careers (see, for example, Neal (1995) and Parent (2000)), see Oyer (2008) for evidence consistent with workers such as the ones we study accumulating industry-specific capital rapidly.
} 
case because it takes place before the firm or worker make a commitment. While this match value is an important determinant of where the person ultimately works, the option value in our model derives from the fact that a new worker may or may not turn out to be a good fit for the industry as a whole.

Productivity $Y$ is an additive function of these three factors. Specifically, $Y=\alpha I_{\{H=1\}}+$ $\beta I_{\{M=1\}}+\varepsilon$. We make two assumptions that are critical to our results and not necessarily intuitive. We will justify both empirically. First, each firm offers a single wage to all new hires. Second, low general ability candidates $(H=0)$ accept job offers with probability 1, while high general ability $(H=1)$ candidates accept offers with probability $p<1$. The first assumption implies that firms only have to be concerned about maximizing $Y$. This is a strong assumption in that it precludes the labor market clearing through wage competition. We can justify this assumption in our context, however, because employers of MBAs generally offer the same wage to all new MBA hires. As we show below, in our data there is no relationship between starting wages and any measures of individual ability (grades, test scores, age, etc.) once we control for employer and job fixed effects. The second assumption captures the idea that high ability candidates have better (and more) opportunities than low ability ones, and hence are less likely to accept a particular offer.

Let $s_{1}$ represent the fraction of first year applicants who have experience in the industry and $s_{2}$ represent the fraction of second year applicants who have experience in the industry. Let $\phi_{a, 2}$ represent the fraction of second year applicants with $H=1$. We will solve for $\phi_{a, 2}$ based on the expected outcomes after the first period. Note that $\phi_{b}$ (i.e., the probability that a person without industry experience will be revealed to have good industry fit, that is, $M=1$ ) does not vary across the two periods because it is a probability that is constant across all workers.

The model plays out according to the following timeline:

- The firm screens one summer intern candidate at random from among applicants.

- After the interview, the firm makes the person an offer at a fixed cost of $\delta$ or chooses not to. If the person is made an offer, he/she accepts if $H=0$ and accepts with probability $p$ if $H=1$.

- If the person is offered the job and accepts, the firm learns the value of $M$ (if the person has no industry experience) over the course of the summer and then either 
offers a permanent job or doesn't. If the person is made an offer at the end of the summer, he/she accepts. ${ }^{8}$

- If the firm does not make a permanent offer to a summer intern, or if it chooses not to employ an intern, or has the internship offer declined, it can screen one second year applicant. The ex-ante expected productivity of a candidate encountered in the second stage of recruiting will be denoted by $\bar{Y}$ (derived in equilibrium).

- After the interview, the firm makes the person an offer at a fixed cost of $\lambda$ or chooses not to.

- If the person is offered the job, he accepts if $H=0$ and accepts with probability $p$ if $H=1$.

- If the person is found to have $M=0$ after being hired for the full-time position, he quits and/or is fired, leading to a replacement cost of $\eta$.

- If the firm ends up hiring no worker for the full-time position, its profits are zero.

\section{$2.2 \quad$ Real Options}

In our model firms value general ability $H$ and industry fit $M$, as well as idiosyncratic fit $\varepsilon$. Firms also have the option to explore an asset (i.e., candidate) at little cost, learn about industry fit, and later "abandon" the asset if it proves to be less valuable than other available candidates. In fact, in our setup firms are provided with real options twice. First, during internship recruiting, a firm is given (at a cost of $\delta$ ) the option to explore a worker during temporary employment, and keep him in a permanent position only if his contribution to firm output turns out to be better than what the firm can expect to get by hiring somebody else at that point in time (namely, $\bar{Y}$ ). The firm can exercise the option to abandon at no cost, as firing an intern is free.

Second, during full-time recruiting, the firm is given (at a cost of $\lambda$ ) the option to offer a full-time job to a candidate, but only keep him in that position if his contribution to the

\footnotetext{
${ }^{8}$ Note that this assumption implies that all stayers receive and accept full-time offers at the end of the internship while some switchers are revealed to be bad industry fits and do not receive full-time offers. Therefore, industry stayers will be more likely to get offers at the end of a summer internship than industry switchers, a prediction supported by the data.
} 
firm's output is above some threshold (given by the firing cost $\eta$ ), which we assume only happens if $M=1$. To exercise the option to abandon (i.e., to fire a candidate with a low enough value), the firm must pay a cost $\eta>0$. This is because firing a full-time employee is costlier, or more time and resource consuming, than firing an intern. ${ }^{9}$

Here, the firm benefits from the upside (i.e., if the candidate's value turns out to be high), but is protected on the downside (i.e., if the candidate's value turns out to be low), particularly at the first and costless exploration stage. For both of these options, the underlying asset is the candidate's contribution to the firm's output, namely $Y=\alpha I_{\{H=1\}}+\beta I_{\{M=1\}}+\varepsilon$, of which $H$ and $\varepsilon$ are known ex-ante, multiplied by the acceptance probability $p$. The uncertainty in the value of the underlying asset is therefore driven by the uncertainty in $M$. For industry stayers, this uncertainty is zero, since we assume $M=1$ for these individuals. For industry switchers, the uncertainty in $M$ depends on $\phi_{b}=\operatorname{Prob}\{M=1 \mid$ industry switcher $\}$ and is given by $\operatorname{var}(M \mid$ industry switcher $)=\phi_{b}\left(1-\phi_{b}\right)$.

Since the value of a call option increases with the current value and variance of the underlying asset and decreases with the strike price, in our setting, the value of having the option to explore and later abandon a particular candidate increases (all else equal) with the firm's current expectation of this candidate's $Y$ (e.g., it increases in the person's $H, \varepsilon$ and acceptance probability $p)$ and with $\operatorname{var}(M \mid$ industry switcher $)=\phi_{b}\left(1-\phi_{b}\right)$, and decreases in $\bar{Y}$ for internship recruiting and in $\eta$ for full-time recruiting.

Note that in this setting the strike price for the internship stage option, i.e. $\bar{Y}$, is endogenous since it depends on how firms make internship offers in the first place, which will influence the composition and quality of the pool of candidates available at the full-time recruiting stage. Furthermore, $\bar{Y}$ also depends on how good candidates turn out to be in terms of industry fit by the end of the internship, which is determined by $\phi_{b}$. Hence, in this model, the parameter $\phi_{b}$ influences two things: the uncertainty in the underlying asset considered by a firm (i.e., the candidate the firm is thinking of making an internship offer to), and the value of the alternative action, which is to hire at the full-time stage (i.e., the value of $\bar{Y}$ ). Therefore, the effect of the uncertainty parameter $\phi_{b}$ on the value of the option to "explore and abandon" at the internship stage is not straightforward, since $\phi_{b}$ has effects on

\footnotetext{
${ }^{9}$ Note that the costs of acquiring these real options to explore workers (i.e., $\delta$ for internship hiring, and $\lambda$ for full-time hiring) are not "market prices" of these options. They are just fixed costs that firms need to pay to be able to explore (and later perhaps abandon) investment opportunities in the realm of human capital.
} 
this option's strike price and on the variance of the underlying asset. While the effect of the adjustment (turnover) cost $\eta$ is clear, in that it makes job offers to risky workers less costly at the temporary employment stage relative to the permanent stage, the effects of worker redeployability and competition for workers are also not straightforward, These variables change the value of the underlying asset (i.e., the expected output resulting from the firm making an offer to the person), as well as the expected value of output $(\bar{Y})$ resulting from waiting and making offers in the second stage. We will now proceed to solving the model to quantify these effects and construct our testable empirical predictions.

\subsection{Implications}

The fact that termination upon the revelation of poor industry fit is costly at the full-time recruiting stage, but costless at the internship stage, implies that the expected value of output resulting from making an offer to a candidate with unknown fit $M$ is higher if the offer is made at the internship stage relative to the final stage. This leads to the following result:

Implication I. Firms value probationary employment arrangements that provide the option to learn about the productivity of potential hires before permanent investment occurs.

To understand the drivers of the value of this option to learn and the patterns in investment decisions it generates, we need to determine the firm's strategy. We do so through backwards induction and start by considering the firm's choices when hiring for full-time positions. The applicant can be any of four types - a high ability switcher, a low ability switcher, a high ability stayer, or a low ability stayer. The firm will make a full-time ("FT") offer to the applicant if $E[Y]>0$, which implies the following rules:

- If the applicant is a high ability switcher ("HASW"), make an offer to him/her if: $p \phi_{b}(\alpha+\beta+\varepsilon)-\lambda-p\left(1-\phi_{b}\right) \eta>0$. This condition will hold with probability $P_{F T o f f e r}^{H A S W}=$ $\frac{1}{2 \sigma}\left(\sigma+\alpha+\beta-\frac{\lambda+p\left(1-\phi_{b}\right) \eta}{p \phi_{b}}\right)$.

- If the applicant is a low ability switcher ("LASW"), make an offer to him/her: $\phi_{b}(\beta+$ $\varepsilon)-\lambda-\left(1-\phi_{b}\right) \eta>0$. This condition will hold with probability $P_{F T o f f e r}^{L A S W}=\frac{1}{2 \sigma}(\sigma+$ $\left.\beta-\frac{\lambda+\left(1-\phi_{b}\right) \eta}{\phi_{b}}\right)$.

- If the applicant is a high ability stayer ("HAST"), make an offer to him/her if: $p(\alpha+$ $\beta+\varepsilon)-\lambda>0$. This condition will hold with probability $P_{\text {FToffer }}^{\text {HAST }}=\frac{1}{2 \sigma}\left(\sigma+\alpha+\beta-\frac{\lambda}{p}\right)$. 
- If the applicant is a low ability stayer ("LAST"), make an offer to him/her if: $\beta+\varepsilon-\lambda>$ 0. This condition will hold with probability $P_{F T o f f e r}^{L A S T}=\frac{1}{2 \sigma}(\sigma+\beta-\lambda)$.

The probability of getting an offer is higher for a random high ability stayer than a random high ability switcher because, for a given $\varepsilon$, the high ability stayer has higher expected productivity. Similarly, the probability of getting an offer is greater for low ability stayers than low ability switchers. Hence the probability of getting an offer will be higher for candidates with industry experience (for whom $M=1$ with certainty). The firm could be more likely to hire a random low ability stayer than a random high ability stayer if high ability workers' acceptance rates are sufficiently low. Specifically, if $p>\frac{\lambda}{\lambda+\alpha}$ then the probability that a random high ability stayer gets an offer is greater than the probability that a low ability stayer gets an offer. The probability of an offer to a high ability switcher will be greater than that for a low ability switcher if $p>\frac{\lambda}{\lambda+\alpha \phi_{b}}$. So, as long as $p$ is high enough, the probability of getting an offer will be increasing in $H$. Therefore, during full-time recruiting, firms will be more likely to make offers to candidates who are proven industry fits (i.e., industry stayers, for whom $M=1$ ) and, as long as their acceptance rate $p$ is high enough, to candidates of high general ability $(H=1)$.

We can now characterize the firm's behavior when it hires summer interns. First, recall that $\bar{Y}$ is the expected value of a person offered a job during the second year recruiting stage. If the expected value of the summer intern is not at least this high, the firm is better off waiting for a full-time applicant. $\bar{Y}$ is the average of each type of worker's value, weighted by the probability that the applicant will be each type, which is Prob(Applicant is low ability stayer $) * \operatorname{Prob}(E[Y]>0 \mid$ low ability stayer $) * E[Y \mid$ low ability stayer with $E[Y]>$ $0]+\operatorname{Prob}($ Applicant is low ability switcher $) * \operatorname{Prob}(E[Y]>0 \mid$ low ability switcher $) * E[Y \mid$ low ability switcher with $E[Y]>0]+\operatorname{Prob}$ (Applicant is high ability stayer $) * \operatorname{Prob}(E[Y]>0 \mid$ high ability stayer) $* E[Y \mid$ high ability stayer with $E[Y]>0]+\operatorname{Prob}$ (Applicant is high ability switcher $) * \operatorname{Prob}(E[Y]>0 \mid$ high ability switcher $) * E[Y \mid$ high ability switcher with $E[Y]>0]$. We can write this as:

$$
\begin{gathered}
\bar{Y}=\frac{\left(1-\phi_{a, 2}\right)}{4 \sigma}\left\{s_{2}(\sigma+\beta-\lambda)^{2}+\left(1-s_{2}\right)\left[\phi_{b} \sigma+\phi_{b} \beta-\lambda-\left(1-\phi_{b}\right) \eta\right]^{2}\right\} \\
+\frac{\phi_{a, 2}}{4 \sigma}\left\{s_{2}[p(\sigma+\alpha+\beta)-\lambda]^{2}+\left(1-s_{2}\right)\left[p \phi_{b}(\sigma+\alpha+\beta)-\lambda-p\left(1-\phi_{b}\right) \eta\right]^{2}\right\}
\end{gathered}
$$


Simple algebra shows that $\bar{Y}$ is increasing (that is, the firm will hold summer interns to a higher standard) in $\alpha, \beta, p, \phi_{a, 2}$, and $\phi_{b}$ and it is decreasing in $\lambda$ and $\eta{ }^{10}$ The effect of the variance $\sigma^{2}$ of idiosyncratic match quality $\varepsilon$ on $\bar{Y}$ is ambiguous. ${ }^{11}$ As with full-time hiring, the firm must choose whether or not to make an internship ("INT") offer to each type of applicant. It will choose as follows:

- If the applicant is a high ability switcher ("HASW"), make an offer to him/her if: $p \phi_{b}(\alpha+\beta+\varepsilon)-\delta>p \phi_{b} \bar{Y}$. This condition will hold with probability $P_{I N T o f f e r}^{H A S W}=$ $\frac{1}{2 \sigma}\left(\sigma+\alpha+\beta-\bar{Y}-\frac{\delta}{p \phi_{b}}\right)$.

- If the applicant is a low ability switcher ("LASW"), make an offer to him/her if: $\phi_{b}(\beta+$ $\varepsilon)-\delta>\phi_{b} \bar{Y}$. This condition will hold with probability $P_{I N T o f f e r}^{L A S W}=\frac{1}{2 \sigma}\left(\sigma+\beta-\bar{Y}-\frac{\delta}{\phi_{b}}\right)$.

- If the applicant is a high ability stayer ("HAST"), make an offer to him/her if: $p(\alpha+\beta+$ $\varepsilon)-\delta>p \bar{Y}$. This condition will hold with probability $P_{I N T \text { TS fer }}^{H A S T}=\frac{1}{2 \sigma}\left(\sigma+\alpha+\beta-\bar{Y}-\frac{\delta}{p}\right)$.

- If the applicant is a low ability stayer ("LAST"), make an offer to him/her if: $\beta+\varepsilon-\delta>$ $\bar{Y}$. This condition will hold with probability $P_{I N T o f f e r}^{L A S T}=\frac{1}{2 \sigma}(\sigma+\beta-\bar{Y}-\delta)$.

We see that, similar to the full-time recruiting stage, during summer internship recruiting, firms will be more likely to make offers to students who are proven industry fits (i.e., industry stayers, for whom $M=1$ ) and, as long as their acceptance rate $p$ is high enough (specifically, $\left.p>\frac{\delta}{\delta+\alpha \phi_{b}}\right)$, to students of high general ability $(H=1)$.

We can now consider how the incentive of the firms to explore and invest in workers with unknown industry fit varies at the two hiring stages, and also, with firm parameters. Using the above conditions necessary for offers to be made at either stage, we can calculate the difference in the firm's preference for stayers versus switchers, for each level of general

\footnotetext{
${ }^{10}$ In addition to a direct positive effect of $\phi_{b}$ on $\bar{Y}, \phi_{b}$ also has an indirect positive effect on $\bar{Y}$ because it increases $s_{2}$. Intuitively, if more outsiders would be a good fit for a particular job, this will increase the fraction of switchers that leave the market after the summer internship and raise the fraction of the pool of full-time applicants that are industry stayers. This, in turn, makes the expected value of a random draw from the full-time pool higher, increasing the value of waiting until the second stage to hire.

${ }^{11} \bar{Y}$ can be increasing or decreasing in $\sigma^{2}$. Increased variance always increases the expected value of the reservation candidate conditional on the candidate being someone the firm prefers to not hiring at all (that is, $E[Y]>0$ ). However, increased variance can either increase (if most candidates are worse than not hiring at all) or decrease (if most candidates are preferable to not hiring) the probability of the new applicant in the second year being better than not hiring at all.
} 
ability, and at each of the two recruiting stages. We get that: $P_{F T o f f e r}^{H A S T}-P_{F T o f f e r}^{H A S W}=\frac{1}{2 \sigma}\left(\frac{1}{\phi_{b}}-\right.$ $1)\left(\eta+\frac{\lambda}{p}\right), P_{\text {FToffer }}^{L A S T}-P_{\text {FToffer }}^{L A S W}=\frac{1}{2 \sigma}\left(\frac{1}{\phi_{b}}-1\right)(\eta+\lambda), P_{\text {INToffer }}^{\text {HAST }}-P_{\text {INToffer }}^{H A S W}=\frac{1}{2 \sigma} \frac{\delta}{p}\left(\frac{1}{\phi_{b}}-1\right)$, and $P_{\text {INToffer }}^{L A S T}-P_{\text {INToffer }}^{L A S W}=\frac{1}{2 \sigma} \delta\left(\frac{1}{\phi_{b}}-1\right)$. Therefore, we have that: $\left[P_{\text {INToffer }}^{\text {HAST }}-P_{\text {INToffer }}^{H A S W}\right]-$ $\left[P_{\text {FToffer }}^{\text {HAST }}-P_{\text {FToffer }}^{H A S W}\right]=\frac{1}{2 \sigma}\left[\frac{\delta}{p}-\frac{\lambda}{p}-\eta\right]<0$ (as long as the cost of writing an internship offer $\delta$ is small relative to the other costs $\lambda$ and $\eta$, which is reasonable). Similarly, we have that: $\left[P_{\text {INToffer }}^{L A S T}-P_{\text {INToffer }}^{L A S W}\right]-\left[P_{\text {FToffer }}^{L A S T}-P_{\text {FToffer }}^{L A S W}\right]=\frac{1}{2 \sigma}(\delta-\lambda-\eta)<0$. In other words, for either level of general ability of the candidates, the relative likelihood that the firm will invest in industry switchers versus stayers is higher at the probationary stage relative to the permanent employment stage. Furthermore, this decrease in the interest to explore unknowns (i.e., industry switchers) from the first to the second stage is particularly high for firms with high turnover costs $\eta$.

The conditions listed above for extending offers at either of the two stages make it clear that a lower probability $\phi_{b}$ that an industry switcher will in fact have good industry fit (i.e., $M=1$ ) will lead to a lower probability that switchers receive employment offers. In other words, uncertainty in workers' productivity hinders investment, at both the probationary and the permanent stage. However, the role of uncertainty on the firms' reluctance to hire is not as pronounced at the probationary stage as it is at the full-time stage, as we obtain that $\frac{d P_{F T \text { offer }}^{L A S W}}{d \phi_{b}}>\frac{d P_{I N T \text { Tffer }}^{L A S W}}{d \phi_{b}}$ and $\frac{d P_{F T \text { offer }}^{H A S W}}{d \phi_{b}}>\frac{d P_{I N T \text { Toffer }}^{H A S W}}{d \phi_{b}}$. Altogether, these observations lead to: Implication II. Higher uncertainty (i.e., $\phi_{b}$ ) and adjustment costs (i.e, $\eta$ ) hinder investment, particularly at the permanent hiring stage, and increase the value of the option to learn.

We will now turn to examining the role of competition for workers on the timing of human capital investment and on the value of probationary employment. Here we capture the degree of competition faced by an employer by the variable $p$, which indicates the likelihood that a high general ability worker will accept this employer's offer. The lower is $p$, the more competition the firm faces when trying to hire good people. The conditions for a firm to extend offers at the two employment stages listed above imply that lowering $p$ (i.e., having the firm face tougher competition) leads to a lowering of the threshold firm-specific fit $\varepsilon$ required for an internship offer (for small offer writing cost $\delta$ ), and at the same time, to an increase in the threshold $\varepsilon$ required for a full-time offer. In other words, if firms face more competition, this will cause more workers in the pool of candidates to receive an internship offer (i.e., $P_{\text {INToffer }}^{H A S T}, P_{\text {INToffer }}^{H A S W}, P_{\text {INToffer }}^{L A S T}$ and $P_{\text {INToffer }}^{L A S W}$ will increase), and fewer to receive an offer 
at the full-time stage (i.e., $P_{F T o f f e r}^{H A S T}$ and $P_{F T o f f e r}^{H A S W}$ will decrease, while $P_{F T o f f e r}^{L A S T}$ and $P_{F T o f f e r}^{L A S W}$ do not change). This effect of competition to make firms more lenient at the probationary stage, relative to the permanent stage, is driven by the fact that at the probationary stage the decision to invest depends on the expected alternative, $\bar{Y}$, which increases with $p$, and thus is lower in more competitive environments. Hence, increased competition increases the relative importance of probationary employment as a channel of investment in workers by firms.

Note that firms recruiting during the full-time stage will be faced with adverse selection due to competition. To see this, we can analyze how the applicant pool differs at the two stages. That is, we can consider $\phi_{a, 2}$. Solving for $\phi_{a, 2}$ explicitly can be done but is excessively complicated algebraically so we focus on comparing the second stage applicant pool to the corresponding first-period pool. To determine how the applicant pool changes between the two stages, we need to determine the probability that each type of worker will leave the market before the second stage. That is, we determine what fraction of high ability switchers, high ability stayers, low ability switchers, and low ability stayers get summer internship offers and, at the end of the internship, an offer of a permanent job. For each type, this is the probability the person is offered a job by the firm that screens her for a summer internship times the probability she accepts times the probability she gets a permanent offer at the end of the summer. We can thus calculate the probability that each of the four types of potential employees leaves the market before the second stage. For a high ability switcher, this probability is $\frac{1}{2 \sigma}\left[p \phi_{b}(\sigma+\alpha+\beta-\bar{Y})-\delta\right]$, for a high ability stayer it is $\frac{1}{2 \sigma}[p(\sigma+\alpha+\beta-\bar{Y})-\delta]$, for a low ability switcher it is $\frac{1}{2 \sigma}\left[\phi_{b}(\sigma+\beta-\bar{Y})-\delta\right]$, and, finally, for a low ability stayer it is $\frac{1}{2 \sigma}(\sigma+\beta-\bar{Y}-\delta)$.

From these expressions we can see that high ability workers are more likely to leave the market if $p>\frac{\sigma+\beta-\bar{Y}}{\sigma+\alpha+\beta-\bar{Y}}$. A sufficient but not necessary condition for this to be true is that, conditional on $\varepsilon$ and switcher/stayer status, the firm prefers a high ability candidate to a low ability candidate when making a full-time offer. That is, when the firm would always prefer a high ability switcher (stayer) candidate with idiosyncratic productivity $\varepsilon^{\prime}$ to a low ability switcher (stayer) with idiosyncratic productivity $\varepsilon^{\prime}$, it will also be the case that high ability candidates are more likely to leave the market before full-time recruiting. Further, it seems likely that the high ability workers that turn down an offer are at least as likely as low ability workers to get a full-time offer at the alternative employer where they accept 
offers. As a result, it must be the case that the fraction of high ability workers that leave the market will be greater than the fraction of low ability workers that leave the market, and hence $\phi_{a, 1}>\phi_{a, 2}$. Firms that wait until the full-time hiring phase to begin hiring will face an adverse selection problem in that there will be fewer high ability workers available after summer internships. ${ }^{12}$

We have been treating the decision about which job to apply for as random for the applicants in the interest of not introducing the complexity required to properly model a two-sided matching process (see Kuhnen (2011) for a model and empirical evidence regarding the applicants' job search process.) That is a reasonable assumption to the extent that we think of all students as potential applicants to all firms and we assume that no firm would ever have chosen an applicant that did not apply to their firm. Under the assumptions we have been using, summer internship "stayers" are always more likely to get a full-time offer than switchers. Hence there will be more stayers accepting jobs immediately after summer internships than switchers. As a result, the pool of available stayers will be smaller for full-time jobs, implying $s_{2}<s_{1} \cdot{ }^{13}$ Therefore, these observations can be summarized as follows:

Implication III. Greater competition for workers (i.e., lower p) speeds up firm investment and increases the value of probationary employment. Corollary: There exists adverse selection at the permanent investment stage.

Finally, we will consider the role of workers' redeployability on the firms' human capital investment decisions and on the value of probationary employment. As noted earlier, if $p$ is high enough (hence the firm faces relatively little competition), then a firm will be more likely to invest in high general ability workers relative to low general ability ones. Specifically, for permanent hiring we have that: $P_{\text {FToffer }}^{\text {HAST }}-P_{\text {FToffer }}^{L A S T}=\frac{1}{2 \sigma}\left[\lambda\left(1-\frac{1}{p}\right)+\alpha\right]$ and $P_{\text {FToffer }}^{\text {HASW }}-P_{\text {FToffer }}^{L A S W}=\frac{1}{2 \sigma}\left[\frac{\lambda}{\phi_{b}}\left(1-\frac{1}{p}\right)+\alpha\right]$ (and is increasing in $\phi_{b}$, because $\left.p<1\right)$. For

\footnotetext{
${ }^{12}$ This suggests some degree of "unraveling" in the MBA market, but not the chronic levels seen in other markets such as certain medical specialties (Niederle and Roth (2003)) and law clerkships (Avery, Jolls, Posner and Roth (2001)). Li and Rosen (1998) develop a model of unraveling in a labor market with one key feature of our model (uncertainty about applicant ability) and without another (probationary hiring, though firms can buy their way out of contracts). They show that unraveling is more dramatic when the applicant pool is smaller, more applicants are relatively talented, and talent is more heterogeneous among applicants.

${ }^{13}$ This requires that we define stayers and switchers based on pre-MBA jobs only. Practically, though, summer internships may expand the potential pool of stayers by generating industry experience for summer internship switchers.
} 
probationary hiring, we obtain that: $P_{\text {INToffer }}^{H A S T}-P_{\text {INToffer }}^{L A S T}=\frac{1}{2 \sigma}\left[\delta\left(1-\frac{1}{p}\right)+\alpha\right]$ and $P_{I N T o f f e r}^{H A S W}-$ $P_{I N T o f f e r}^{L A S W}=\frac{1}{2 \sigma}\left[\frac{\delta}{\phi_{b}}\left(1-\frac{1}{p}\right)+\alpha\right]$ (and is increasing in $\left.\phi_{b}\right)$. In other words, the threshold in terms of firm-specific fit that must be met by a candidate is higher for low general ability workers relative to high general ability ones, particularly if there is less uncertainty about their industry fit. That is, general ability is valuable for converting an application into an offer, especially in the case of industry stayers or for higher $\phi_{b}$. Hence, greater asset redeployability (i.e., higher general ability) leads to more investment at both the probationary and the permanent stage, if firms face relatively low competition, and this is effect is particularly strong in the case of less risky workers. Also, note that, because firms with higher $p$ (and $\alpha$ ) are more likely to make offers to high ability candidates and to get them to accept these offers, high ability candidates will disproportionately end up at these firms. This leads to positive assortative matching between firms and workers. However, this matching will be imperfect, with some low general ability workers at high prestige $p$ (and high productivity $\alpha$ ) firms due to the idiosyncratic matching parameter $\varepsilon$. These observations lead to our final result, namely:

Implication IV. Higher worker redeployability (i.e., higher H) leads to higher investment if firms face low enough competition (i.e., high enough p), particularly in the presence of less uncertainty about industry fit. Corollary: There exists imperfect positive assortative matching, as high ability workers are more likely to work for high prestige (p) or high productivity ( $\alpha$ ) firms.

\section{Data}

We test the model's predictions using a novel dataset describing detailed aspects of the recruiting process conducted by a large number of globally-known firms at a top business school in the U.S. The data span three MBA cohorts during 2007-2009, encompassing 1,482 job applicants and 383 firms, covering both internship and full-time recruiting. It provides details regarding the firms' identity and industry, job openings posted, as well as the candidates' personal and work background, training while in business school, applications sent during both recruiting stages, and offers received. See Kuhnen (2011) for more details regarding the dataset. Table 1 provides basic summary statistics of these 1,482 students.

We describe firms using various measures of industry, prestige and size. We use a coarse 
breakdown of industry, putting firms into one of six categories - consulting, finance, general corporations, technology, government/non-profit and other services (mainly law firms), as well as a fine classification scheme, based on the 60-industry breakdown used by the business school providing the data. We define a firm as prestigious (and therefore likely to have high offer acceptance rate $p$ ) if the firm is listed in the Fortune MBA 100 annual rankings during 2007-2009. If in a given sample year a firm is ranked in the top 100 according to these surveys, then we refer to it as a prestigious employer. ${ }^{14}$ This appears to be a valid way to capture firm desirability, given that in our sample, offers made by firms on the Fortune list have a significantly higher chance to be accepted than offers made by other firms: $52 \%$ versus $40 \%$ in the case of internships, and $61 \%$ versus $44 \%$ in the case of full-time jobs (these differences are significant at $p<0.01)$.

To capture the firm turnover cost $\eta$ we use firm size, as smaller firms are likely to face higher costs if they need to fire and replace employees. For example, this may happen because smaller firms may not have a dedicated human resources department. They may be less able to redeploy workers in different divisions, relative to more complex firms, as documented empirically by Tate and Yang (2011), or they may be more financially constrained and thus more likely to fire workers following changes in project choices (Giroud and Mueller (2012)). We measure size based on three dimensions: annual revenues, number of employees, and years since founded. The latter is particularly useful in the case of privately held companies, for which the sales and employees figures are not always available. These figures are collected from Compustat in the case of publicly-traded firms, and from databases compiled by Hoovers, Manta.com, and Vault.com in the case of private firms. We assign the firms in the sample to deciles with respect to each of these size proxies, and also construct an overall size proxy as the average of the firm's standing (in terms of decile) across these three size measures.

The recruiting process at the business school providing the data for this study is well structured. For both internships and full-time jobs, students can apply to obtain an interview slot during on-campus recruiting in two stages. In the first stage, referred to as "closed", they can submit resumes to companies that will offer on-campus recruiting. Employers then select whom to invite for interviews based on the students' resumes. ${ }^{15}$ This process

\footnotetext{
${ }^{14}$ The rankings are available at: http://money.cnn.com/magazines/fortune/mba100/2009/full_ist/.

${ }^{15}$ Unfortunately, we do not have information on which students were selected for interviews through the
} 
is costless to students. In a second stage, called the "open" or "bidding" system, students can bid a limited number of points (out of an annual endowment of 800 points) to obtain an interview slot. Therefore, in this second stage, obtaining an interview with a desired employer is costly to the student (in terms of bid points). The dataset contains all the bids that each student placed for interview slots for either internships or full-time jobs, as well as information about whether or not the bids were successful (i.e., higher or equal to the clearing bid for that contest). On-campus recruiting for full-time positions occurs at the beginning of the students' second year in the MBA program, between September and December. On-campus recruiting for summer internships occurs during the January-March period of the students' first year in the MBA program.

\section{Empirical Results}

We start by presenting evidence regarding some of the key assumptions of the model, and then move on to test the four main theoretical implications regarding human capital investment decisions.

\subsection{Evidence Regarding Model Assumptions}

Each firm offers a single wage wage to all new hires. This assumption implies that wages offered for jobs taken upon finishing school do not depend on individuals' ability or industry experience. An institutional detail supporting this assumption is that employers that recruit on campus are required to post details such as the job title, location, and salary at the very beginning of the recruiting season (and before seeing any candidates). As shown in the regression model in Table 2, the data confirms that starting salaries (i.e., those characterizing the first year of employment after graduate school) are specific to the position available, and do not depend on characteristics of the person who receives the employment offer. ${ }^{16}$ Specifically, controlling for class, industry, job source, job location, and company-job title fixed effects, we find no evidence that the GPA, quality of undergraduate institution attended,

closed system. We know if a student applied to a job opening through this system, and if he/she got a job offer, but data on the intermediate interview stage is not available.

\footnotetext{
${ }^{16}$ We only have data concerning starting salaries. It is likely that after working for a company for a while, an employee will be compensated based on proven performance.
} 
industry experience, age, gender, or international student status of the person receiving the full-time offer are related to the offered wage (either in logs or levels). Furthermore, in the data only $10.8 \%$ of starting full-time wages are renegotiated (the corresponding figure for internships is $1.72 \%$ ). Not surprisingly, the wage renegotiation frequency is $3.7 \%$ higher in the case of male candidates, in line with the finding in Babcock and Laschever (2003) that men are better than women at asking for higher pay. ${ }^{17}$ While in general rare, renegotiations of starting wages are more frequent for cohorts graduating during good economic times, compared to those graduating during recessions. Specifically, the frequency of renegotiations is $13.01 \%$ for the class of 2007, and $8.27 \%$ for the class of 2009 (the difference is statistically significant at $p<0.05$ ). The renegotiation frequency for the class of 2008 (graduating several months before the beginning of the financial crisis in September 2008) is $10.02 \%$.

Low general ability candidates $(H=0)$ accept job offers with probability 1 , while high ability candidates accept offers with probability $p<1$. While a literal interpretation of this assumption is not valid (in the sense that in reality low ability students do not always accept a particular offer), the key empirical relevance of the assumption is that, for our model to be valid, it must be the case that high ability (i.e., $H=1$ ) candidates accept offers for internships or full-time jobs with a lower probability than low ability (i.e., $H=0$ ) candidates. In other words, Assumption 2 can be restated as $1-p>0$. Table 3 confirms this assumption, showing that high ability candidates (defined as those with above average GPA) receive more offers than low ability candidates. Based on the number of offers received, we estimate that the offer acceptance rate of high ability candidates is lower than that of low ability candidates by $12 \%$ in the case of internships, and by $10 \%$ in the case of full-time offers. These differences can be interpreted as measuring the value of $1-p$ in the data.

A large fraction of job applicants have unknown industry fit, which creates uncertainty regarding their future productivity. Among all applications sent for jobs, the fraction that come from industry switchers is $89 \%$ in the case of internships, and $86 \%$ in the case of full-time jobs. This illustrates the fact that for the majority of potential candidates, firms face uncer-

\footnotetext{
${ }^{17}$ In a different sample of MBA students, Bertrand, Goldin and Katz (2010) document a rising gap in earnings between men and women after graduation, caused by gender differences with respect to training during business school, career interruptions, and weekly hours worked.
} 
tainty regarding the industry specific skills of these individuals.

All else equal, firms prefer to hire students with high general ability and experience in their industry. Table 4 shows the results of probit models predicting whether an application resulted in an offer, for each stage of the recruiting process - summer hiring, general fulltime hiring, and full-time offers made to summer interns. For each applicant/firm pair, we define the applicant to be an industry stayer if the applicant worked in the firm's industry (using either the fine or the coarse industry classification schemes) before entering business school (and so that this measure will be comparable across the two recruiting seasons, we do not change the definition based on the summer internship experience). We define applicants to be of high ability $(H=1)$ if the person's total two-year GPA during the MBA program is above the school average. ${ }^{18}$

Columns 1 and 2 of Table 4 show probits of job offer probability for summer internships and full-time jobs, respectively. As we would expect, offers of both type are more likely as general ability $H$ or industry fit $M$ increase. With respect to general ability, we find that increasing the GPA by 1 point (using a 4-point scale) increases the probability of an internship application resulting in an offer by $6 \%$. This is a large effect, given the overall application-to-offer conversion rate for internships is $5.6 \%$. Similarly, increasing the GPA by 1 point increases the probability of a full-time application resulting in an offer by $3 \%$, a large effect given that the application-to-offer conversion rate at the full-time recruiting stage is $3.4 \%$. With respect to industry fit, we document that applications from industry stayers are $3 \%$ more likely to result in offers at both recruiting stages. These effects are economically large and statistically significant $(p<0.01)$. Column 3 of Table 4 indicates that industry stayers will be more likely to get offers at the end of a summer internship than industry switchers. The table shows that, relative to industry switchers, industry stayers have a $19 \%$ higher probability of converting an internship into full-time employment $(p<0.01){ }^{19}$, in

\footnotetext{
${ }^{18}$ Using only the GPA for classes taken during the first quarter of the first year in the MBA program (i.e., right before students apply for internships) yields virtually the same results, as the GPA is highly persistent from quarter to quarter.

${ }^{19}$ Note, however, that our model does not capture all the effects of general ability $H$. In the model, firms only learn about industry fit over the summer, so general ability (which is publicly known at all times) does not affect the probability of a summer intern getting a full-time offer (conditional on the person getting a summer internship offer in the first place). However, the table shows that high GPA students are substantially more likely to get offers at the end of an internship than low GPA students.
} 
line with the model assumption that a fraction of switchers are revealed to have low industry fit during probationary employment.

\subsection{Evidence Regarding Model Predictions}

We now turn to testing whether the four broad implications of the model are supported by the data.

Implication I. Firms value probationary employment arrangements that provide the option to learn about the productivity of potential hires before permanent investment occurs.

Indeed, we find that employers highly value the option to learn about candidates, by making significant use of cheap probationary employment - namely, summer intern positions after the students' first year in the MBA program. The vast majority (94\%) of students work in a probationary position during the summer between the first and second year of the MBA program, and $44 \%$ of candidates who receive probationary employment convert that into fulltime job offers. In $68 \%$ of these cases, the offer is accepted. Furthermore, industry switchers who obtain internship offers but do not manage to convert these into permanent employment are $38 \%$ more likely, relative to the successful intern switchers, to seek permanent jobs in a different industry from that of the internship. In other words, information revelation during summer employment is, at least in part, related to industry fit.

Implication II. Higher uncertainty (i.e., $\phi_{b}$ ) and adjustment costs (i.e, $\eta$ ) hinder investment, particularly at the permanent hiring stage, and increase the value of the option to learn.

As predicted, we find that the relative likelihood of investing in industry switchers versus stayers is higher during internship recruiting relative to full-time recruiting. Furthermore, this decrease in the interest to explore industry switchers from the first to the second hiring stage is particularly high for firms with high turnover costs $\eta$. Finally, a lower probability $\phi_{b}$ of having good industry fit leads to a lower probability that firms will make offers to switchers, particularly at the full-time stage.

To measure the relative preference of firms for switchers versus stayers, we calculate the fraction of offers made to industry switchers, at each of the two hiring stages. As predicted, we find that industry switchers receive a higher fraction of internship offers (63\%) relative to offers made during full-time recruiting (52\%). This difference is significant at $p<0.01$. Also, the multivariate probit models in columns 1 and 2 of Table 4 show that the positive 
impact of being an industry stayer on the likelihood that an application will result in an offer is greater at the full-time stage than at the internship stage. The coefficients are similar for the two groups but, given the underlying difference application success probability ( $5.6 \%$ for internship applications vs. $3.4 \%$ for full-time job applications), the effect is much greater at the full-time recruiting stage. Industry experience roughly doubles the success probability of full-time applicants, while only increasing the internship applicants' success rate by half. These results provide strong evidence that firms are more willing to explore switchers through probationary employment, rather than through full-time employment.

Implication II also states that the preference exhibited during internship recruiting (relative to the full-time recruiting stage) for industry switchers relative to industry stayers will be stronger when turnover costs $(\eta)$ are higher. The evidence in Table 5 is consistent with this prediction. The table displays simple comparisons across high and low $\eta$ firms of the fraction of offers made to industry switchers at the internship and full-time stages. We use both the coarse (first two columns) and the fine (columns three and four) industry classification scheme to define whether an applicant is a switcher or a stayer. In the top panel we measure $\eta$ based on the firm's overall size decile (i.e., the aggregate size measure based on sales, number of employees and years since founded), since larger firms are likely to have processes in place that can speed up the firing and replacement of workers. As a robustness check, in the bottom panel of Table 5 we use firm prestige as an alternative measure of turnover costs on the assumption that high prestige firms can more easily fill openings. As before, we find that offers to industry outsiders are more common at the summer phase for all types of firms. Moreover, the drop in interest in industry switching applicants between the internship and the full-time recruiting stage is greater for higher $\eta$ firms, whether we measure $\eta$ based on firm size or firm prestige. We find that high $\eta$ firms are between $11 \%$ and $13 \%$ less likely to make offers to industry outsiders at the full-time stage, relative to the internship stage. In the case of low $\eta$ firms, the corresponding drop in interest in switchers is only $6 \%$ to $9 \%$, depending on the $\eta$ proxy and on whether we use the coarse or the fine industry classification scheme. These aggregate figures suggest that exploration is more valuable early on, in particular if the cost of late-stage failure (i.e., turnover cost due to low industry fit) is high.

Further evidence that high turnover costs hinder permanent investment comes from the probit models in Table 6, where the dependent variable indicates whether a firm's offer at 
the full-time stage was given to an industry switcher, rather than to a stayer. In the three specifications we use various measures of firm size as proxies for turnover cost $\eta$, based on firm sales, number of employees, or a composite of these and the age of the firm. For all three measures we find a positive relationship between making the offer to an industry switcher and firm size. These relationships are significant and economically meaningful in that an increase of one size decile increases the probability of the offer going to a switcher by two to three percentage points. To put this effect in perspective, the base probability of an offer going to an industry switcher is $52 \%$.

The final aspect of Implication II is that higher uncertainty (lower $\phi_{b}$ ) about industry fit makes investment in switchers less likely, particularly at the full-time stage. We generate a proxy for the likelihood $\phi_{b}$ of a switcher being a good fit for each of the six broad industry classifications by determining what fraction of industry switching summer interns receive fulltime offers. We define high $\phi_{b}$ industries to be those where it is more likely that an internship offered to a switcher will result in a full-time offer. The "high $\phi_{b}$ " broad industry areas are Consulting $\left(\phi_{b}=50 \%\right)$ and Finance $\left(\phi_{b}=48 \%\right)$. Low $\phi_{b}$ industry areas include General Corporations $\left(\phi_{b}=36 \%\right)$ and Technology $\left(\phi_{b}=40 \%\right)$.

According to the theory, we should find that being an industry switcher is particularly detrimental for getting an offer in industries where $\phi_{b}$ is low, and that this is best seen during the full-time recruiting stage. The probit models in Table 7 show evidence consistent with this prediction. The table shows results from probits similar to the specifications in Table 4, except we split each sample into high $\phi_{b}$ and low $\phi_{b}$ industries. As we already saw in Table 4, we observe that being an industry stayer increases the chance of converting an application into an offer. In other words, industry switchers are disadvantaged when they apply for jobs at either stage. Importantly, they are more disadvantaged in low $\phi_{b}$ industries compared to high $\phi_{b}$ industries, and specifically during full-time recruitng. At that stage, the drop in the probability that the firm will make an offer to the candidate if he/she is a switcher, rather than a stayer, is $5 \%$ in low $\phi_{b}$ industries, but only $2 \%$ in high $\phi_{b}$ industries. Another way to see this effect is to look among all offers, and check whether firms in high $\phi_{b}$ industries have more of their offers going to switchers. Indeed, in unreported tests, we observe a $10 \%$ increase in the probability that an observed offer is to an industry switcher, and not to a stayer, among offers made in high $\phi_{b}$ industry areas such as Finance and Consulting relative to low $\phi_{b}$ industry areas such as Technology and General Corporations. 
Implication III. Greater competition for workers (i.e., lower p) speeds up firm investment and increases the value of probationary employment. Corollary: There exists adverse selection at the permanent investment stage.

We find that higher competition increases the number of job offers that firms make at the internship stage, relative to the full-time stage, increasing the importance of probationary employment as a channel for investment in human capital. For each employer in the sample, classified as either prestigious (high $p$ ) or not prestigious (low $p$ ), we calculate the number of offers they make to job seekers during the internship recruiting stage, and during full-time recruiting. Our theory implies that for low $p$ employers, who face more competition, the internship channel is more important than the full-time channel, relative to high $p$ employers. Consistent with this idea, we find that low $p$ firms are significantly less likely, relative to high $p$ firms, to return and make offers in the second stage of recruiting. Both types of firms use the probationary channel, but the firms that hire also at the full-time recruiting stage tend to be the prestigious (high $p$ ) ones. Specifically, $69 \%$ of firms making offers at both stages are not prestigious (low $p$ ), while $98 \%$ of firms that do not return at the full-time stage are not prestigious. (In the overall sample, $92 \%$ of firms are classified as not prestigious). This suggests that indeed, the threat of competition makes firms more inclined to invest at the probationary stage, and less so at the permanent stage.

We can also use another method to measure the degree of competition faced by firms and test the implication that in more competitive environments, probationary employment becomes relatively more valuable as a hiring tool. Firms recruiting during 2007 and 2008 faced higher competition for workers (corresponding thus to a lower $p$ ) than firms recruiting during the economic downturn in 2009 (see Kuhnen (2011)). Hence we can also test Implication III by looking at the differences in the probabilities of making offers in the 2007-2008 subsample, relative to 2009. As shown in Table 8, internship applications received by firms were indeed more likely to result in offers during 2007 and 2008, relative to 2009 (6.2\% relative to $4.5 \%$, significantly different at $p<0.001)$. Note, however, that firms are also more likely to offer jobs to applicants at the full-time stage during 2007-2008, relative to 2009, a result which may indicate that the former are years where the productivity parameters $\alpha$ and $\beta$ may also be higher (hence differences in hiring may not be due solely to differences in the level of competition given by $p$ ). In general, and not surprisingly, we also observe that the success rate for internship applications is higher than for full-time jobs, during both subsamples. 
Furthermore, as predicted, we document that the quality of the candidate pool is lower at the permanent recruiting stage relative to the internship stage. Table 9 shows evidence consistent with this prediction. The overall GPA of 307 candidates who choose not to participate in on campus full-time recruiting is 3.50, whereas the GPA of the 1100 who participate is 3.44 (the difference is significant at $p<0.001$ ). This indicates that, at least along this dimension of general ability, the full-time recruiting pool is of lower quality than the pool of candidates who are no longer seeking jobs at that time. While this may not seem like a large difference, grade dispersion is not all that great at this school. The 0.06 GPA difference is roughly a quarter of one standard deviation. To understand whether there is also a worsening of the candidate pool at the full-time recruiting stage in terms of industry experience, we calculate the percentage of candidates who participate in the on campus full-time recruiting process, conditional on being an industry switcher at the internship stage. Of those who choose not to apply for full-time jobs in their second year of the MBA program (21\% of candidates), $80 \%$ had interned for companies in an industry (using the school's 60 industry categorization scheme) different from that where they worked before business school, and therefore were industry switchers in the first recruiting stage. For the remaining candidates, who did apply to jobs during the on-campus recruiting process, $85 \%$ were industry switchers at the internship stage (the difference is significant at $p<$ 0.03). Among all candidates recruiting at the internship stage, $84 \%$ were industry switchers. Therefore, the pool of candidates actively seeking jobs at the full-time recruiting stage is of lower quality, in terms of industry experience, than the pool of candidates who have completed the job seeking process after the summer internship stage. These results indicate that there exists some unraveling in terms of general ability and industry expertise during the two recruiting stages, which leads those firms recruiting in the full-time stage to face adverse selection in the candidate pool.

Implication IV. Higher worker redeployability (i.e., higher H) leads to higher investment if firms face low enough competition (i.e., high enough p), particularly in the presence of less uncertainty about industry fit. Corollary: There exists imperfect positive assortative matching, as high ability workers are more likely to work for high prestige (p) or high productivity ( $\alpha$ ) firms.

We find that in general firms are more likely to invest in more redeployable workers, namely those with high general ability as measured by their GPA, relative to less redeployable 
ones, for both probationary and permanent jobs. This can be seen in the probit models in Table 4, which show that having more general human capital (i.e., a higher GPA) increases the probability that an application will result in an offer, at the internship stage, as well as at the full-time stage.

Implication IV also states that general ability is particularly valuable for converting an application into an offer in the case of industry stayers (and, among switchers, for those with higher $\phi_{b}$ ). To test this, for each of the two hiring stages we calculate the fraction of successful applications that come from high GPA students, and from low GPA students. We do this for applications of industry stayers, and then separately for applications from industry switchers. The results are summarized in Table 10 and support the theoretical implication. Take for example the case of internship recruiting. Among industry stayers, a high GPA candidate has a $4.9 \%$ higher probability to get an offer compared to a low GPA candidate. Among industry switchers, the advantage of high GPA students is only $2.1 \%$. It is $1.9 \%$ if these are applicants in low $\phi_{b}$ industries, and $2.2 \%$ in high $\phi_{b}$ industries, namely consulting and finance. Full-time recruiting patterns also offer support (albeit weaker) of the theoretical implication that high general ability is valued by firms, particularly if there is no uncertainty about industry fit.

Finally, we verify the corollary there exists imperfect positive assortative matching. As predicted, the data show that better people tend to work at better firms. Specifically, we find that $60 \%$ of those accepting full-time offers at "high prestige" firms have high GPAs compared to $47 \%$ of those joining firms that are not prestigious.

\subsection{Caveats and Limitations}

The model does not capture all the factors involved in corporate hiring, as our main goal was to focus on the real options aspect of this process. One example of an oversimplication in the model is that we assumed that reservation profits ( 0 in the full-time stage and $\bar{Y}$ for the internship stage) are identical across firms. Presumably "better" firms (in terms of $p$ or $\alpha$, for example) would be able to hold out for better workers given they would have better applicants from other sources (other business schools, for example). Also, there are likely to be other forms of heterogeneity across firms (such as the number of positions available or the number of people available to interview) that are not captured by parameters $p, \alpha, \beta, \eta$ and $\phi_{b}$. For example, in the data the likelihood that an application for a full-time job results in a 
job offer may not just depend on the firm's probability $p$ of having its offer accepted, but may also depend on how many applications were sent to the firm per available full-time position. Unfortunately, we do not know how many positions were available at a given firm. Another oversimplification in the model exposed by the empirical work is our assumption that the students' general ability (as proxied by GPA, for example) is known when candidates are first seen. In reality, however, as firms spend more time with a candidate (e.g., during the summer internship), they get to learn this general ability more precisely. In the data, we in fact observe that a high GPA increases the likelihood that a summer internship is converted into a full-time job (see Table 4), which the model would not predict.

The data have limitations that lead to caveats about the internal and external validity of the analysis. First, the offers are self-reported by students. The career office at the school that provided the data works very hard to encourage students to provide details of their offers. However, some students may not report their market outcomes at all and others may report with some error (such as not listing all offers). Second, a substantial amount of the job search by students at this school is done through channels other than on-campus recruiting. In these cases, we do not have any information about firms' preferences because we do not observe who applies to these firms. While we do not think that these issues bias our results substantially (if anything, the measurement error would imply any relationships in the data are likely to be stronger than our analysis suggests), we do not know for sure. Third, the external validity of our analysis is limited by the fact that our data set covers job seekers at one school and the particular firms that choose to conduct recruiting activities there.

\section{Conclusion}

Theoretically and empirically we show that firms consider potential employees using a real options approach, as they do when making other types of investment decisions. Given the prevalence of probationary employment in the economy, we model the decision to invest in human capital in a setting where firms can explore and learn about worker productivity before making costly long-term commitments. The model generates predictions concerning the effects of uncertainty, adjustment costs, competition, and asset redeployability on human capital investment. We test these predictions using a unique dataset covering recruiting activity at a top U.S. business school. We find that firms value probationary employment 
arrangements that provide the option to learn about the productivity of potential hires before permanent investment occurs. Higher uncertainty and adjustment costs hinder permanent investment and increase the value of the option to learn. Greater competition for workers speeds up firm investment and increases the value of probationary employment. Higher worker redeployability leads to more investment, if firms face low competition, particularly if uncertainty about productivity is lower.

Our paper has two main contributions. Theoretically, we bring together ideas from the real options literature in corporate finance and from the personnel and labor economics literature, to understand the process by which firms make human capital investment decisions. Empirically, we add to the limited literature concerning the drivers of firms' hiring strategies and firm-worker matching. Our model and evidence point to the existence of both similarities and differences between the drivers of human and physical capital investments. 


\section{References}

Abel, A. B., Dixit, A. K., Eberly, J. C. and Pindyck, R. S.: 1996, Options, the value of capital, and investment, Quarterly Journal of Economics 111(3), 753-777.

Agrawal, A. K. and Matsa, D. A.: 2011, Labor unemployment risk and corporate financing decisions, Working paper .

Avery, C., Jolls, C., Posner, R. A. and Roth, A. E.: 2001, The market for federal judicial law clerks, The University of Chicago Law Review 2001, 793-902.

Babcock, L. and Laschever, S.: 2003, Women don't ask: Negotiation and the gender divide, Princeton University Press.

Bandiera, O., Guiso, L., Prat, A. and Sadun, R.: 2010, Matching firms, managers, and incentives, Working paper.

Berk, J. B., Stanton, R. and Zechner, J.: 2010, Human capital, bankruptcy and capital structure, Journal of Finance 65, 891-926.

Bertrand, M., Goldin, C. and Katz, L. F.: 2010, Dynamics of the gender gap for young professionals in the financial and corporate sectors, American Economic Journal: Applied Economics 2(3), 228-255.

Booth, A. L., Francesconi, M. and Frank, J.: 2002, Temporary jobs: Sepping stones or dead ends?, The Economic Journal 112, F189F213.

Brennan, M. J. and Schwartz, E. S.: 1985, Evaluating natural resource investments, Journal of Business 58(2), 135-157.

Bulan, L., Mayer, C. and Somerville, C. T.: 2009, Irreversible investment, real options, and competition: Evidence from real estate development, Journal of Urban Economics 65, 237-251.

Caballero, R. J.: 1991, On the sign of the investment-uncertainty relationship, American Economic Review 81(1), 279-288.

Cunningham, C. R.: 2007, Growth controls, real options and land development, Review of Economics and Statistics 89(2), 343-358.

Dixit, A. K. and Pindyck, R.: 1994, Investment Under Uncertainty, Princeton University Press. 
Eisfeldt, A. L. and Papanikolaou, D.: forthcoming, Organization capital and the cross-section of expected returns, Journal of Finance .

Farber, H. S. and Gibbons, R.: 1996, Learning and wage dynamics, Quarterly Journal of Economics 111, 1007-1047.

Foote, D. A. and Folta, T. B.: 2002, Temporary workers as real options, Human Resource Management Review 12, 579-597.

Gabaix, X. and Landier, A.: 2008, Why has CEO pay increased so much?, Quarterly Journal of Economics 123(1), 49-100.

Giroud, X. and Mueller, H. M.: 2012, Capital and labor reallocation inside firms, Working paper .

Graham, J., Harvey, C. R. and Puri, M.: 2010, Managerial attitudes and corporate actions, Working paper.

Greenwald, B. C.: 1986, Adverse selection in the labor market, Review of Economic Studies 53, 325347.

Grenadier, S. and Malenko, A.: 2010, A bayesian approach to real options: The case of distinguishing between temporary and permanent shocks, Journal of Finance 65(5), 1949-1986.

Grenadier, S. R.: 2002, Option exercise games: An application to the equilibrium investment strategies of firms, Review of Financial Studies 15(3), 691-721.

Guell, M. and Petrongolo, B.: 2007, How binding are legal limits? Transitions from temporary to permanent work in spain, Labour Economics 14, 153-183.

Guiso, L. and Parigi, G.: 1999, Investment and demand uncertainty, Quarterly Journal of Economics 114(1), 185-227.

Hendricks, W., DeBrock, L. and Koenker, R.: 2003, Uncertainty, hiring, and subsequent performance: The NFL draft, Journal of Labor Economics 21, 857-886.

Houseman, S. N.: 2001, Why employers use flexible staffing arrangements: Evidence from an establishment survey, Industrial and Labor Relations Review 55(1), 149-170.

Jovanovic, B.: 1979, Job matching and the theory of turnover, Journal of Political Economy 87, 972-990. 
Kahn, L. B. and Lange, F.: 2011, Employer learning, productivity, and the earnings distribution: Evidence from performance measures, Working paper .

Kaniel, R., Massey, C. and Robinson, D. T.: 2010, The importance of being an optimist: Evidence from labor markets, NBER Working paper 16328 .

Kaplan, S., Klebanov, M. M. and Sorensen, M.: forthcoming, Which CEO characteristics and abilities matter?, Journal of Finance .

Kuhnen, C. M.: 2011, Searching for jobs: Evidence from MBA graduates. Northwestern University.

Lazear, E. P.: 1998, Hiring risky workers, in I. Ohashi and T. Tachibanaki (eds), Internal Labour Markets, Incentives, and Employment, St. Martin's Press, New York.

Levin, J.: 2002, Multilateral contracting and the employment relationship, Quarterly Journal of Economics 117(3), 1075-1103.

Li, H. and Rosen, S.: 1998, Unraveling in matching markets, American Economic Review 88(3), 371-387.

McDonald, R. and Siegel, D.: 1986, The value of waiting to invest, Quarterly Journal of Economics 101, 707-727.

Moel, A. and Tufano, P.: 2002, When are real options exercised? an empirical study of mine closings, Review of Financial Studies 15(1), 35-64.

Neal, D.: 1995, Industry-specific human capital: Evidence from displaced workers, Journal of Labor Economics 13, 653-677.

Niederle, M. and Roth, A. E.: 2003, Unraveling reduces mobility in a labor market: Gastroenterology with and without a centralized match, Journal of Political Economy 111, 1342-1352.

Ouimet, P. and Zarutskie, R.: 2011, Acquiring labor, Working paper .

Oyer, P.: 2008, The making of an investment banker: Stock market shocks, career choice, and lifetime income, Journal of Finance 63, 2601-2628.

Oyer, P. and Schaefer, S.: 2011, Personnel economics: Hiring and incentives, in O. Ashenfelter and D. Card (eds), The Handbook of Labor Economics, Vol. 4b, North-Holland, Great Britain.

Paddock, J. L., Siegel, D. R. and Smith, J. L.: 1988, Option valuation of claims on real assets: The case of offshore petroleum leases, Quarterly Journal of Economics 103, 479-508. 
Parent, D.: 2000, Industry-specific capital and the wage profile: Evidence from the national longitudinal survey of youth and the panel study of income dynamics, Journal of Labor Economics 18, 306-323.

Quigg, L.: 1993, Empirical testing of real option-pricing models, Journal of Finance 48, 621-640.

Sapienza, P., Maestripieri, D. and Zingales, L.: 2009, Gender differences in financial risk aversion and career choices are affected by testosterone, Proceedings of the National Academy of Sciences 106(36), 1526815273.

Schultz, T. W.: 1961, Investment in human capital, American Economic Review 51, 1-17.

Segal, L. M. and Sullivan, D. G.: 1997, The growth of temporary services work, Journal of Economic Perspectives 11(2), 117-136.

Shue, K.: 2011, Executive networks and firm policies: Evidence from the random assignment of mba peers, Working paper.

Tate, G. and Yang, L.: 2011, The bright side of corporate diversification: Evidence from internal labor markets, Working paper .

Tervio, M.: 2008, The difference that CEOs make: An assignment model approach, American Economic Review 98(3), 642-668.

Titman, S.: 1985, Urban land prices under uncertainty, American Economic Review 75(3), 505-514.

Trigeorgis, L.: 1996, Real Options, MIT Press.

Waldman, M.: 1984, Job assignments, signaling, and efficiency, RAND Journal of Economics 15, 255-267.

Williams, J. T.: 1993, Equilibrium and options on real assets, Review of Financial Studies 6(4), 825850. 
Table 1: Summary statistics for job candidates.

\begin{tabular}{lrr}
\hline & Mean & St.Dev. \\
\hline GPA $_{i}$ & 3.45 & 0.28 \\
Top100Undergrad $_{i}$ & 0.48 & 0.50 \\
Age $_{i}$ (years) & 30.11 & 2.19 \\
Male $_{i}$ & 0.66 & 0.47 \\
InternationalStudent $_{i}$ & 0.39 & 0.49 \\
\hline$N$ & \multicolumn{2}{c}{1482} \\
\hline
\end{tabular}

Table 2: OLS wage regression. Keeping the company and job characteristics fixed, salaries for full-time job offers do not depend on the ability of the person receiving the offer.

\begin{tabular}{lrr}
\hline Dependent variable & Wage $_{i}$ & Ln $(\text { Wage })_{i}$ \\
\hline$G P A_{i}^{M B A}$ & -1011.57 & -0.01 \\
& $(-1.01)$ & $(-1.04)$ \\
${\text { Top } 100 \text { Nndergrad }_{i}}$ & 332.39 & 0.00 \\
IndustryStayer $_{i}$ & $(0.73)$ & $(0.53)$ \\
& -201.90 & -0.01 \\
InternationalStudent $_{i}$ & $(-0.38)$ & $(-0.92)$ \\
& -293.09 & -0.00 \\
Male $_{i}$ & $(-0.54)$ & $(-0.40)$ \\
& 522.53 & 0.01 \\
Age $_{i}$ & $(1.03)$ & $(1.02)$ \\
& -30.89 & -0.00 \\
Constant & $(-0.24)$ & $(-0.40)$ \\
& 93878.65 & 11.45 \\
Class FEs $_{\text {Industry FEs }}$ & $(9.28)^{* * *}$ & $(98.05)^{* * *}$ \\
Job Source FEs $_{\text {Job Location FEs }}$ & Yes & Yes \\
Company-Job title FEs & Yes & Yes \\
\hline$R^{2}$ & Yes & Yes \\
Observations & Yes & Yes \\
\hline
\end{tabular}


Table 3: High ability candidates have a lower offer acceptance probability than low ability candidates.

\begin{tabular}{lrr}
\hline & $\begin{array}{r}\text { Number of internship offers } \\
\text { and acceptance probability }\end{array}$ & $\begin{array}{r}\text { Number of full-time offers } \\
\text { and acceptance probability } \\
\text { (if in full-time recruiting) }\end{array}$ \\
\hline $\begin{array}{l}\text { High ability candidates } \\
\text { (GPA above average) }\end{array}$ & $\begin{array}{r}1.98 \\
\mathrm{~N}=784 \text { people }\end{array}$ & $\begin{array}{r}1.48 \\
\mathrm{~N}=568 \text { people }\end{array}$ \\
\hline $\begin{array}{l}\text { Low ability candidates } \\
\text { (GPA below average) }\end{array}$ & 1.60 & 1.29 \\
\hline$\Delta$ Offers High vs. Low Ability & $\mathrm{N}=698$ people & $\mathrm{N}=532$ people \\
\hline Probability Offer Acceptance & $0.38^{* * *}(p<0.01)$ & $0.19^{* * *}(p<0.01)$ \\
High vs. Low Ability & $\frac{1}{1.98}-\frac{1}{1.60}$ & $\frac{1}{1.48}-\frac{1}{1.29}$ \\
Estimate for $(1-p)$ & $12 \%$ & $10 \%$ \\
\hline
\end{tabular}

Table 4: Who gets offers? Probit models, marginal effects are reported. The dependent variable is equal to one for applications that resulted in an offer. Standard errors are robust to heteroskedasticity and clustered by job. Clustering by student yields results of similar statistical significance. Linear probability models yield similar results.

\begin{tabular}{|c|c|c|c|}
\hline \multirow[t]{2}{*}{$\begin{array}{l}\text { Dependent } \\
\text { variable }\end{array}$} & \multicolumn{3}{|c|}{$\begin{array}{c}\text { Indicator equal to } 1 \\
\text { for applications resulting in offers }\end{array}$} \\
\hline & Internships & Full-time Jobs & FT jobs through internship \\
\hline$\overline{G P A_{i}}$ & 0.06 & 0.03 & 0.31 \\
\hline & $(8.87)^{* * *}$ & $(5.13)^{* * *}$ & $(5.61)^{* * *}$ \\
\hline IndustryStayer $_{i}$ & 0.03 & 0.03 & 0.19 \\
\hline & $(5.41)^{* * *}$ & $(4.83)^{* * *}$ & $(4.64)^{* * *}$ \\
\hline Male $_{i}$ & -0.02 & -0.01 & -0.06 \\
\hline & $(-4.86)^{* * *}$ & $(-3.97)^{* * *}$ & $(-1.70)^{*}$ \\
\hline International $_{i}$ & -0.02 & -0.02 & -0.06 \\
\hline & $(-8.09)^{* * *}$ & $(-6.96)^{* * *}$ & $(-1.88)^{*}$ \\
\hline$A g e_{i}$ & -0.00 & -0.00 & 0.01 \\
\hline & $(-0.92)$ & $(-0.32)$ & $(0.79)$ \\
\hline Class FEs & Yes & Yes & Yes \\
\hline Industry FEs & Yes & Yes & Yes \\
\hline$\overline{P s e u d o ~} R^{2}$ & 0.03 & 0.08 & 0.08 \\
\hline Observations & 23800 & 10654 & 1296 \\
\hline $\begin{array}{l}\text { Observed application } \\
\text { success frequency }\end{array}$ & $5.6 \%$ & $3.4 \%$ & $44 \%$ \\
\hline
\end{tabular}


Table 5: Switchers are more attractive as summer interns than as full-time hires when turnover costs are higher. In the top panel we use firm size as a proxy for turnover cost $\eta$. Observations are split based on whether the firm's overall size decile is above the mean (i.e., indicating a low $\eta$ ) or below the mean (i.e., indicating a high $\eta$ ). As a robustness check, in the bottom panel we use firm prestige as an alternative proxy for turnover costs (i.e., prestigious firms are likely to have low $\eta$, while the others have high $\eta$ ).

\begin{tabular}{|c|c|c|c|c|}
\hline $\begin{array}{l}\text { \% offers made to } \\
\text { industry switchers }\end{array}$ & $\begin{array}{l}\text { Low } \eta \text { firms } \\
\text { (High Size) }\end{array}$ & $\begin{array}{l}\text { High } \eta \text { firms } \\
\text { (Low Size) }\end{array}$ & $\begin{array}{c}\text { Low } \eta \text { firms } \\
\text { (High Size) }\end{array}$ & $\begin{array}{l}\text { High } \eta \text { firms } \\
\text { (Low Size) }\end{array}$ \\
\hline & \multicolumn{2}{|c|}{ Broad industry classification } & \multicolumn{2}{|c|}{ Fine industry classification } \\
\hline Internships & $62 \%$ & $60 \%$ & $86 \%$ & $80 \%$ \\
\hline Full-time Jobs & $55 \%$ & $49 \%$ & $77 \%$ & $69 \%$ \\
\hline Difference & $7 \% * *$ & $11 \%{ }^{* * *}$ & $9 \%^{* * *}$ & $11 \%^{* * *}$ \\
\hline \multirow[t]{2}{*}{$\begin{array}{l}\% \text { offers made to } \\
\text { industry switchers }\end{array}$} & $\begin{array}{l}\text { Low } \eta \text { firms } \\
\text { (Prestigious) }\end{array}$ & $\begin{array}{c}\text { High } \eta \text { firms } \\
\text { (Non-prestigious) }\end{array}$ & $\begin{array}{l}\text { Low } \eta \text { firms } \\
\text { (Prestigious) }\end{array}$ & $\begin{array}{c}\text { High } \eta \text { firms } \\
\text { (Non-prestigious) }\end{array}$ \\
\hline & \multicolumn{2}{|c|}{ Broad industry classification } & \multicolumn{2}{|c|}{ Fine industry classification } \\
\hline Internships & $60 \%$ & $63 \%$ & $81 \%$ & $86 \%$ \\
\hline Full-time Jobs & $54 \%$ & $50 \%$ & $72 \%$ & $73 \%$ \\
\hline Difference & $6 \% * *$ & $13 \% \%^{* * *}$ & $9 \%$ *** & $13 \%^{* * *}$ \\
\hline
\end{tabular}

Table 6: Turnover cost $\eta$ and the relative preference for stayers vs. switchers during oncampus full-time recruiting. Probit models, marginal effects reported. Dependent variable is equal to 1 if offer recipient is an industry switcher (using five broad industry categories in columns 1-3, and 60 fine industry categories in columns 4-6). Robust standard errors clustered by candidate.

\begin{tabular}{|c|c|c|c|c|c|c|}
\hline Dependent variable & \multicolumn{6}{|c|}{ Indicator equal to 1 if offer recipient is an industry switcher } \\
\hline & \multicolumn{3}{|c|}{ Coarse industry categories } & \multicolumn{3}{|c|}{ Fine industry categories } \\
\hline Sales Decile & 0.03 & & & 0.02 & & \\
\hline$($ low $\eta)$ & $(3.08)^{* * *}$ & & & $(2.45)^{* *}$ & & \\
\hline Employees Decile & & 0.02 & & & 0.01 & \\
\hline$($ low $\eta)$ & & $(2.11)^{* *}$ & & & $(1.09)$ & \\
\hline Overall Size Decile & & & 0.03 & & & 0.01 \\
\hline$($ low $\eta)$ & & & $8)^{* * *}$ & & & $(1.60)$ \\
\hline Class FEs & Yes & Yes & Yes & Yes & $\overline{\text { Yes }}$ & Yes \\
\hline Industry FEs & Yes & Yes & Yes & Yes & Yes & Yes \\
\hline$R^{2}$ & 0.04 & 0.04 & 0.04 & 0.09 & 0.08 & 0.08 \\
\hline Observations & 513 & 535 & 543 & 505 & 527 & 535 \\
\hline
\end{tabular}


Table 7: Risk of mismatch $\phi_{b}$ and investment decisions. Probit models, marginal effects are reported. The dependent variable is equal to one for applications that resulted in an offer. Standard errors are robust to heteroskedasticity and clustered by job. Clustering by student yields results of similar statistical significance. Linear probability models yield similar results.

\begin{tabular}{|c|c|c|c|c|}
\hline \multirow[t]{2}{*}{$\begin{array}{l}\text { Dependent } \\
\text { variable }\end{array}$} & \multicolumn{4}{|c|}{$\begin{array}{l}\text { Indicator equal to } 1 \\
\text { for applications resulting in offers }\end{array}$} \\
\hline & $\begin{array}{r}\text { Full-time stage, } \\
\text { high } \phi_{b} \text { industries } \\
(\text { e.g., Finance, }) \\
\text { Consulting) }\end{array}$ & $\begin{array}{r}\text { Full-time stage, } \\
\text { low } \phi_{b} \text { industries } \\
\text { (e.g., Tech, } \\
\text { General Corp.) }\end{array}$ & $\begin{array}{r}\text { Internship stage, } \\
\text { high } \phi_{b} \text { industries } \\
\text { (e.g., Finance, } \\
\text { Consulting) }\end{array}$ & $\begin{array}{r}\text { Internship stage, } \\
\text { low } \phi_{b} \text { industries } \\
\text { (e.g., Tech, } \\
\text { General Corp.) }\end{array}$ \\
\hline \multirow[t]{2}{*}{$\overline{G P A_{i}}$} & 0.02 & 0.03 & 0.06 & 0.05 \\
\hline & $(3.78)^{* * *}$ & $(3.57)^{* * *}$ & $(6.14)^{* * *}$ & $(6.44)^{* * *}$ \\
\hline \multirow[t]{2}{*}{ IndustryStayer $_{i}$} & 0.02 & 0.05 & 0.03 & 0.03 \\
\hline & $(3.38)^{* * *}$ & $(3.63)^{* * *}$ & $(3.91)^{* * *}$ & $(3.69)^{* * *}$ \\
\hline \multirow[t]{2}{*}{ Male $_{i}$} & -0.01 & -0.02 & -0.02 & -0.02 \\
\hline & $(-1.85)^{*}$ & $(-3.82)^{* * *}$ & $(-2.70)^{* * *}$ & $(-4.07)^{* * *}$ \\
\hline \multirow[t]{2}{*}{ International $_{i}$} & -0.02 & -0.02 & -0.02 & -0.03 \\
\hline & $(-5.23)^{* * *}$ & $(-4.45)^{* * *}$ & $(-4.57)^{* * *}$ & $(-6.83)^{* * *}$ \\
\hline \multirow[t]{2}{*}{$A g e_{i}$} & -0.00 & -0.00 & -0.00 & -0.00 \\
\hline & $(-0.11)$ & $(-0.35)$ & $(-0.84)$ & $(-0.49)$ \\
\hline Class FEs & Yes & Yes & Yes & Yes \\
\hline Industry FEs & Yes & Yes & Yes & Yes \\
\hline Pseudo $R^{2}$ & 0.08 & 0.07 & 0.04 & 0.03 \\
\hline Observations & 5721 & 4933 & 10237 & 13563 \\
\hline
\end{tabular}

Table 8: Competition for workers and likelihood of investment.

\begin{tabular}{lrrr}
\hline & \multicolumn{3}{c}{ Fraction of applications resulting in offers } \\
\hline & & High competition & Low competition \\
& All cohorts & cohorts (2007 \& 2008) & cohort (2009) \\
\hline Internship stage & $5.6 \%$ & $6.2 \%$ & $4.5 \%$ \\
Full-time stage & $3.4 \%$ & $4.6 \%$ & $1.5 \%$ \\
\hline
\end{tabular}


Table 9: Adverse selection at the full-time recruiting stage. Participants in the on-campus recruiting process for full-time jobs have lower general ability and are more likely to be industry switchers relative to individuals who are done seeking employment after the internship stage.

\begin{tabular}{lrr}
\hline & GPA & $\begin{array}{r}\% \text { who were switchers at } \\
\text { internship stage }\end{array}$ \\
\hline $\begin{array}{l}\text { Participated in full-time } \\
\text { recruiting on campus }\end{array}$ & 3.44 & $85 \%$ \\
\hline $\begin{array}{l}\text { Did not participate in full-time } \\
\text { recruiting on campus }\end{array}$ & 3.50 & $80 \%$ \\
\hline Difference & $(N=307)$ & \\
\hline
\end{tabular}

Table 10: Redeployability, uncertainty about industry fit, and likelihood of investment.

\begin{tabular}{|c|c|c|c|}
\hline & & \multicolumn{2}{|c|}{ Fraction of applications resulting in offers } \\
\hline & & Internship & Full-time \\
\hline & & Stage & Stage \\
\hline \multirow[t]{3}{*}{ Industry Stayers } & High GPA & $10.6 \%$ & $7.2 \%$ \\
\hline & Low GPA & $5.7 \%$ & $5.4 \%$ \\
\hline & Difference & $4.9 \%^{* * *}$ & $1.8 \%^{*}$ \\
\hline \multirow[t]{3}{*}{ Industry Switchers } & High GPA & $6.3 \%$ & $3.5 \%$ \\
\hline & Low GPA & $4.2 \%$ & $2.3 \%$ \\
\hline & Difference & $2.1 \% \%^{* * *}$ & $1.2 \%^{* * *}$ \\
\hline \multirow{3}{*}{$\begin{array}{l}\text { Industry Switchers, } \\
\text { high } \phi_{b} \text { industries } \\
\text { (e.g., Consulting, Finance) }\end{array}$} & High GPA & $6.0 \%$ & $2.7 \%$ \\
\hline & Low GPA & $3.8 \%$ & $1.7 \%$ \\
\hline & Difference & $2.2 \%^{* * *}$ & $1.0 \%^{* *}$ \\
\hline \multirow{3}{*}{$\begin{array}{l}\text { Industry Switchers, } \\
\text { low } \phi_{b} \text { industries } \\
\text { (e.g., Tech, General Corp.) }\end{array}$} & High GPA & $6.4 \%$ & $4.5 \%$ \\
\hline & Low GPA & $4.5 \%$ & $2.9 \%$ \\
\hline & Difference & $1.9 \% \%^{* * *}$ & $1.6 \%^{* *}$ \\
\hline
\end{tabular}

